\title{
In-hospital Outcome of Percutaneous Coronary Intervention among Very Elderly Patients with Ischemic Heart Disease in a Dedicated Cardiac Hospital
}

\author{
Mohammad Arifur Rahman ${ }^{1}$, Afzalur Rahman², Mohammd Mahbubur Rahman ${ }^{3}$, Farhana Ahmed ${ }^{4}$, \\ Md Kamrul Hasan ${ }^{5}$, Jinat Farjana ${ }^{6}$, Md.Azizur Rahaman Majumder ${ }^{7}$, Ahmed Mamunul Huq ${ }^{8}$, Atikur Rahman ${ }^{9}$
}

\begin{abstract}
:
Background: Cardiovascular disease, and ischemic heart disease (IHD), is a major cause of morbidity and mortality in the very elderly patients ( $>80$ years) worldwide. These patients represent a rapidly growing cohort presenting for percutaneous coronary intervention $(\mathrm{PCl})$, now constituting more than one in five patients treated with $\mathrm{PCl}$ in real-world practice. Furthermore, they often have greater ischemic burden than their younger counterparts, suggesting that they have greater scope of benefit from coronary revascularization therapy. The elderly usually has higher prevalence of co morbidities and more often experience complications during and after revascularization procedures. Our aim was to evaluate clinical outcomes of $\mathrm{PCl}$ in patients older than 80 years, compared to their younger counterparts.
\end{abstract}

Materials and methods: From July 2017 to July 2018 we included 212 patients with IHD purposively in Cardiology department of National Institute of Cardiovascular Diseases undergone $\mathrm{PCl}$ who were divided into 2 groups according to age: $\mathrm{e}$ " 80 years $(n=74)$ and $<80$ years $(n=$ 138). Baseline clinical characteristics, indications for coronary intervention, in hospital outcomes were obtained. Study endpoint were Renal impairment, MI, LVF, emergency revascularization and death.
Results: Very elderly patients were more frequently male $(86 \%)$ and nonsmoker at present $(41 \%$ vs. $63 \%$, $\mathrm{p}=0.003)$, had higher prevalence of hypertension $(60 \%$ vs. $50 \%, p<0.13)$, and more often presented with NSTEMI (54\% vs. $23 \%$, p<0.001). Elderly group had higher incidence of TVD and LM disease (36\% vs. $26 \%$ and $9.5 \%$ vs. $2.9 \%$, $\mathrm{p}=0.07)$ and more incidence of ostial $(16.2 \%$ vs. $5.1 \%, p=0.007)$ and calcified lesions $(31.1 \%$ vs. $14.5 \%$, $p=0.004$ ). Procedural success (TIMI III) were high in both groups, but still lower in the elderly as compared to younger group $(95 \%$ vs. $97 \%, p=0.65)$. Very elderly patients had higher incidence of post PCI bleeding, CIN, MI, LVF and death $(9.5 \%$ vs.6.1\%, $8.2 \%$ vs. $3.7 \%, 6.8 \%$ vs. $5.8 \%, 9.5 \%$ vs. $5.1 \%$ and $5.4 \%$ vs. $3.6 \%, p=0.07$ ), whereas emergency revascularization were higher in younger group $(5.4 \%$ vs. $6.5 \%, p=0.07)$.

Conclusion: Very elderly patients aged $\geq 80$ years face more vascular site complications during $\mathrm{PCI}$, usually have more LM and TVD with more ostial and calcified lesions in comparison with younger group. Though procedural success is similar with younger group, they face more post PCI CIN, LVF and MI. Repeat revascularization was higher in younger group.

Key words: Outcome of PCl, Very elderly patients, Ischemic Heart Disease

(Bangladesh Heart Journal 2020; 35(1): 61-65)

1. Junior Consultant, Dept. of Cardiology, National Institute of Cardiovascular Diseases, Dhaka, Bangladesh

2. Director and Professor (Ex.),Depat. of Cardiology, National Institute of Cardiovascular Diseases, Dhaka, Bangladesh

3. Professor, Department of Cardiology, National Institute of Cardiovascular Diseases, Dhaka, Bangladesh

4. Assistant Professor, Department of Cardiology, National Institute of Cardiovascular Diseases, Dhaka, Bangladesh

5. Department of Cardiology, National Institute of Cardiovascular Diseases, Dhaka, Bangladesh

6. Department of Cardiology, National Institute of Cardiovascular Diseases, Dhaka, Bangladesh

7. Department of Cardiology, National Institute of Cardiovascular Diseases, Dhaka, Bangladesh.

8. Department of Cardiology, National Institute of Cardiovascular Diseases, Dhaka, Bangladesh.

9. Department of Cardiology, National Institute of Cardiovascular Diseases, Dhaka, Bangladesh

Address of Correspondence: Mohammad Arifur Rahman, Junior Consultant, Cardiology, National Institute of Cardiovascular Diseases, Dhaka, Bangladesh. Mobile: +880 1711666030. Email: drarif79@yahoo.com. 


\section{Introduction:}

Population ageing is a major public health issue in developing countries. Aging is an independent major risk factor of ischemic heart disease. Coronary artery disease is a leading cause of mortality and morbidity in very elderly patients. ${ }^{1}$ Morbidity and mortality from ischemic heart disease are strongly associated with age, especially for people over 80 years old (very elderly patients). Elderly patients usually have comorbidities such as chronic kidney disease, hypertension, and diabetes mellitus. ${ }^{2,3}$ They are more likely to have tortuous vasculature, arterial calcification, and complex coronary lesions .4,5 Hence, percutaneous coronary intervention $(\mathrm{PCl})$ for the elderly is always challenging.

In-hospital mortality among very elderly aged e"80 years or very elderly patients after $\mathrm{PCl}$ was reported to be up to $4.1 \%$ in 2007.5 The rates were $3.8 \%$ in the National Cardiovascular Network data (1994-1997)6 and 3.8\% in the American College of Cardiology/National Cardiovascular Data Registry (1998-2000), ${ }^{6}$ indicating a 4-fold increase in risk. PCl environments such as expert cardiac catheterization laboratories, transradial access, and drug-eluting stent are generally believed to be able to improve the outcome of $\mathrm{PCl}$ in this patient group. ${ }^{7,8}$ However, the safety and efficacy of $\mathrm{PCl}$ in very elderly patients remain controversial. ${ }^{9,10}$ therefore, the objective of this study was to observe the clinical outcomes of multivessel coronary intervention in very elderly patients hospitalized for acute coronary syndrome and compared to that with younger counterparts

\section{Materials and methods}

From July 2017 to July 2018 we included 212 patients purposively with IHD undergoing Coronary angiogram followed by Percutaneous coronary intervention where indicated in Cardiology department of National Institute of Cardiovascular Diseases. Study populations were divided into 2 groups according to age; e" 80 years ( $n=$ 74) were in group I and $<80$ years $(n=138)$ were in group II. Baseline clinical characteristics including age, sex, risk factors of coronary artery diseases (Hypertension, Diabetes Mellitus, Dyslipidemia and Smoking), indications for coronary intervention (Chronic stable angina, unstable angina, Non STEMI, STEMI), Angiographic findings, in hospital outcomes were evaluated. All patients received a heparin bolus (500010000 IU). Routine antiplatelets treatment included long term Aspirin, and Clopidogrel for at least one year or preferably lifelong. Study endpoint was in-hospital outcome such as Vascular site complication (bleeding that requires transfusion, retroperitoneal hemorrhage and nonhemorrhagic complications such as pseudoaneurysm, arteriovenous fistula, arterial dissection, thrombosis and limb ischemia), Contrast induced nephropathy(Elevation of serum creatinine of more than $25 \%$ or e" $0.5 \mathrm{mg} / \mathrm{dl}$ from baseline within 48 h), Myocardial infarction, left ventricular failure, emergency revascularization and Death) \& 1 year follow up for Myocardial infarction, Repeat revascularization and death.

Data obtained from the study were analyzed and significance of differences were estimated by using statistical methods. Variables were analyzed by chisquare test and t-test where applicable. $P$ value $P<0.05$ were considered as significant. Statistical analyses were performed with SPSS, version 16.0 (SPSS Inc).

\section{Results and discussion}

Study population were divided into two groups. 74 patients were in group I aged e" 80 years and (138 patients were in group II aged $<80$ years. Mean age was $83.65 \pm 4.53$ years for group I and $56.44 \pm 9.67$ years for group II. Male were significantly higher among very elderly (86.5\% vs.73.9\%, $p=0.03)$. Among the risk factors diabetes mellitus and dyslipidemia were significantly higher in very elderly $(62.2 \%$ vs. $37.7 \%$ for diabetes, $p=0.001$ and $60.8 \%$ vs $50.6 \%$ for dyslipidemia, $p=0.001$ ), whereas Current smoking were significantly higher in younger group (41.9\% vs.63.0\%, $\mathrm{p}=0.003)$.

Among the population of group I and groups II STEMI, NSTEMI, UA and CSA were $12(16.2 \%)$ vs. 24 (17.4\%), 40 $(54.1 \%)$ vs. $32(23.2 \%), 12(16.2 \%)$ vs. $44(31.9 \%)$ and $10(13.5 \%)$ vs. $38(27.5 \%)$ respectively. NSTEMI was significantly higher among very elderly patients whereas STEMI, UA, CSA were significantly higher in younger group $(p=0.001)$. Echocardiographic findings showed left ventricular ejection fraction (LVEF) were significantly higher in very elderly patients $(16.2 \%$ vs. $6.5 \%, p=0.024)$ (Table I).

Coronary angiogram of study population (Table II) showed triple vessel disease(TVD)(36.1\% vs. $26.1 \%)$ and left main disease(LMD) $(9.5 \%$ vs. $2.9 \%)$ were more in very elderly patients whereas SVD and DVD were more in younger group, although the differences were not statistically significant $(p=0.70)$. On the other hand, ostial $(16.2 \%$ vs. $2.9 \%, p=0.007)$ and calcified $(31.1 \%$ vs. $14.5 \%, 0.004)$ lesions were significantly higher in very elderly patients.

Study of in-hospital outcomes (Table III) showed vascular site complications were significantly higher in very elderly patients $(9.5 \%$ vs. $6.1 \%, p=0.031)$. Post $\mathrm{PCI} \mathrm{MI}(6.8 \%$ vs. $5.8 \%)$, LVF (9.5\% vs. $5.1 \%), \operatorname{CIN}(8.2 \%$ vs. $3.6 \%)$ and 
Table-I

Baseline characteristics of study population

\begin{tabular}{lccc}
\hline Variables & Age $\geq 80$ years $(\mathrm{n}=74)$ & Age $<80$ years $(\mathrm{n}=138)$ & P value \\
\hline Mean age (years) & $83.65 \pm 4.53$ & $56.44 \pm 9.67$ & \\
Male & $64(86.5 \%)$ & $102(73.9 \%)$ & 0.03 \\
Hypertension & $45(60.8 \%)$ & $69(50.6 \%)$ & 0.132 \\
Diabetes mellitus & $46(62.2 \%)$ & $52(37.7 \%)$ & 0.001 \\
Dyslipidemia & $42(56.8 \%)$ & $73(52.9 \%)$ & 0.31 \\
Current smoking & $31(41.9 \%)$ & $87(63.0 \%)$ & 0.003 \\
Diagnosis & $12(16.2 \%)$ & $24(17.4 \%)$ & $<0.001$ \\
ST elevation MI & $40(54.1 \%)$ & $32(23.2 \%)$ & \\
Non ST elevation MI & $12(16.2 \%)$ & $44(31.9 \%)$ & \\
Unstable angina & $38(27.5 \%)$ & \\
Chronic stable angina & $10(13.5 \%)$ & & \\
Echocardiographic finding & $12(16.2 \%)$ & $9(6.5 \%)$ & \\
LV EF $<50 \%$ & & & \\
\hline
\end{tabular}

Table-II

Angiographic findings of study population

\begin{tabular}{lccc}
\hline Variables & Age $\geq 80$ years $(\mathrm{n}=74)$ & Age $<80$ years $(\mathrm{n}=138)$ & $\mathrm{P}$ value \\
\hline Single vessel disease & $21(28.4 \%)$ & $50(36.2 \%)$ & 0.70 \\
Double vessel disease & $19(25.4 \%)$ & $48(34.8 \%)$ & \\
Triple vessel disease & $27(36.1 \%)$ & $36(26.1 \%)$ & \\
Left main disease & $7(9.5 \%)$ & $4(2.9 \%)$ & \\
Lesion Characteristics & & $7(5.1 \%)$ & 0.007 \\
Ostial & $12(16.2 \%)$ & $20(14.5 \%)$ & 0.004 \\
Calcified & $23(31.1 \%)$ & & \\
\hline
\end{tabular}

Table-III

In-hospital outcome

\begin{tabular}{lccc}
\hline Variables & Age $\geq 80$ years $(\mathrm{n}=74)$ & Age $<80$ years $(\mathrm{n}=138)$ & $\mathrm{P}$ value \\
\hline Vascular site complication & $10(9.5 \%)$ & $7(6.1 \%)$ & 0.031 \\
Post PCI infarction & $5(6.8 \%)$ & $8(5.8 \%)$ & 0.07 \\
Post PCI LV failure & $7(9.5 \%)$ & $7(5.1 \%)$ & \\
Emergency revascularization & $4(5.4 \%)$ & $9(6.5 \%)$ & \\
Death & $4(5.4 \%)$ & $5(3.6 \%)$ & \\
Contrast nephropathy & $8(8.2 \%)$ & $5(3.6 \%)$ & \\
TIMI III & $73(95.6 \%)$ & $137(97.3 \%)$ & \\
\hline
\end{tabular}

death $(5.4 \%$ vs. $3.6 \%)$ were numerically $(p=0.07)$ higher in very elderly patients whereas post $\mathrm{PCI}$ TIMI III flow (95.6\% vs.97.3\%) and emergency revascularization were higher in younger group.

\section{Discussion:}

Some previous studies have compared the outcomes of $\mathrm{PCl}$ in patients with different ages and found that adverse events are increased with age and severity of the disease. ${ }^{11,12}$ Therefore, physicians are often reluctant to treat elderly patients aggressively. Elderly patients are usually referred late for revascularization. In addition, $\mathrm{PCl}$ in very elderly patients is often performed to relieve symptoms rather than for complete revascularization, although they have more extensive coronary disease than their younger counterparts. ${ }^{13}$ In addition, the elderly do 
not receive proper diagnosis or treatment in a timely manner for a number of reasons, including economic conditions. ${ }^{14}$ Therefore, coronary disease in the elderly is more progressive, and the prognosis of $\mathrm{PCl}$ in the elderly is usually poor than that of their younger counterparts.

Our results revealed that very elderly patients undergoing $\mathrm{PCl}$ due to ACS were mostly hypertensive male, and usually present with NSTEMI and poor LV function. They face more bleeding and vascular site complications during $\mathrm{PCl}$, usually have more LM and TVD with more ostial and calcified lesions in comparison to younger group. Though procedural success is similar with younger group, very elderly patients undergo more post $\mathrm{PCl}$ bleeding, CIN, LVF and MI. Repeat revascularization was higher in younger group.

The clinical characteristics were not significantly different between the two groups. The incidence of major complications that would increase the mortality was not significantly different between the two groups. Despite of the high risk factor with old age, previous reports on invasive treatment in the elderly with coronary artery disease have shown that $\mathrm{PCl}$ results in the elderly are not inferior compared to $\mathrm{PCl}$ in younger patients. ${ }^{15}$

The APPROACH (Alberta Provincial Project for Outcomes Assessment in Coronary Heart Disease) Registry has demonstrated long-term survival benefit in very elderly patients with coronary artery disease who are treated with either surgical or percutaneous revascularization compared to those who are treated with medical therapy. ${ }^{16}$ Thrombolysis in Myocardial infarction (TIMI) trial has also demonstrated that invasive strategy can provide early symptom relief and better quality of life compared to those who receive optimal medical treatment (Reference) ${ }^{17}$ In patients aged $>80$ years with acute coronary syndrome, early $\mathrm{PCl}$ has been shown to be able to achieve better outcomes than medical treatment alone. ${ }^{17-19}$ In the era of drug eluting stent (DES), Hassani et al. ${ }^{20}$ have demonstrated a low mortality rate in very elderly patients with stable angina $(4.1 \%)$ at 6 months.

Some studies have found that mortality rates in acute coronary syndrome $(15 \%)$ and ST elevation in myocardial infarction $31 \%$ ) among very elderly patients remained significantly high. ${ }^{21}$ Meanwhile, other studies have shown that mortality and incidence of major complications after $\mathrm{PCl}$ in very elderly patients with acute coronary syndrome are not higher than those in their younger counterparts. ${ }^{22}$

\section{Conclusion:}

Very elderly patients undergoing $\mathrm{PCl}$ due to ACS are mostly hypertensive male, usually present with NSTEMI and poor LV function. They face more bleeding and vascular site complications during $\mathrm{PCl}$, usually have more LM and TVD with more ostial and calcified lesions in comparison with younger group. Though procedural success is similar with younger group, very elderly patients experience more post $\mathrm{PCl}$ bleeding, CIN, LVF and MI. Emergency repeat revascularization was higher in younger group. Although immediate interventional procedure related complications are more in very elderly patients, long term outcomes seem to be promising \& comparable with younger counterparts. As it is a single center, non-randomized, small sample study further studies into the optimal pharmacologic and interventional ACS management strategies in very elderly patients are warranted.

\section{Limitations}

This study was conducted in Cardiology department of National Institute of cardiovascular diseases which was a single center study. In this study small numbers of subjects were included fulfilling pre-defined inclusion and exclusion criteria. Sampling method was purposive and follow up time was short.

Conflict of Interest - None.

\section{References:}

1. Keller NM, Feit F. Atherosclerotic heart disease in the elderly. Curr Opin Cardiol 1995;10:427-33.

2. Taddei CF, Weintraub WS, Douglas JS Jr, Ghazzal $Z$, Mahoney E, Thompson T, et al. Influence of age on outcome after percutaneous transluminal coronary angioplasty. Am J Cardiol 1999;84: 245-51.

3. Cohen HA, Williams DO, Holmes DR Jr, Selzer F, Kip KE, Johnston JM, et al. Impact of age on procedural and 1-year outcome in percutaneous transluminal coronary angioplasty: a report from the NHLBI Dynamic Registry. Am Heart J 2003;146:513-9.

4. Dziewierz A, Siudak Z, Rakowski T, Dubiel JS, Dudek D. Age-related differences in treatment strategies and clinical outcomes in unselected cohort of patients with ST-segment elevation myocardial infarction transferred for primary angioplasty. J Thromb Thrombolysis 2012;34:214-21.

5. Batchelor WB, Anstrom KJ, Muhlbaier LH, Grosswald R, Weintraub WS, O'Neill WW, et al. 
Contemporary outcome trends in the elderly undergoing percutaneous coronary interventions: results in 7,472 very elderly patients. National Cardiovascular Network Collaboration. J Am Coll Cardiol 2000;36: 723-30.

6. Dangas GD, Singh HS. Primary percutaneous coronary intervention in very elderly patients: navigate with caution. Heart 2010; 96:813-4.

7. Santana JO, Haft JI, LaMarche NS, Goldstein JE. Coronary angioplasty in patients eighty years of age or older. Am Heart J 1992;124:13-8.

8. Jolly SS, Yusuf S, Cairns J, Niemela K, Xavier D, Widimsky P, et al. Radial versus femoral access for coronary angiography and intervention in patients with acute coronary syndromes (RIVAL): a randomised, parallel group, multicentre trial. Lancet 2011;377:1409-20.

9. Minai K, Horie H, Takahashi M, Nozawa M, Kinoshita M. Long-term outcome of primary percutaneous transluminal coronary angioplasty for low-risk acute myocardial infarction in patients older than 80 years: a single-center, open, randomized trial. Am Heart J 2002;143:497-505.

10. Klein LW, Block P, Brindis RG, Mckay CR, McCallister BD, Wolk M, et al. Percutaneous coronary interventions in very elderly patients in the American College of Cardiology- National Cardiovascular Data Registry: development of a nomogram predictive of in-hospital mortality. J Am Coll Cardiol 2002;40:394-402.

11. Feldman DN, Gade CL, Slotwiner AJ, Parikh M, Bergman G, Wong SC, et al. Comparison of outcomes of Percutaneous coronary interventions in patients of three age groups $(<60,60$ to 80 , and $>80$ years) (from the New York State Angioplasty Registry). Am J Cardiol 2006;98:1334-9.

12. Weintraub WS, Veledar E, Thompson T, Burnette J, Jurkovitz C, Mahoney E. Percutaneous coronary intervention outcomes in very elderly patients during the stent era (National Cardiovascular Network). Am J Cardiol 2001;88:1407-10, A6.

13. Spertus JA, Salisbury AC, Jones PG, Conaway DG, Thompson RC. Predictors of quality-of life benefit after Percutaneous coronary intervention. Circulation 2004;110:3789-94.

14. Lee HT, Shin J, Lim YH, Kim KS, Kim SG, Kim JH, et al. Health-related quality of life in coronary heart disease in Korea: the Korea National Health and Nutrition Examination Survey 2007 to 2011. Angiology 2015;66:326-32.

15. Coronary angioplasty versus medical therapy for angina: the second Randomised Intervention Treatment of Angina (RITA-2) trial. RITA-2 trial participants. Lancet 1997;350: 461-8.

16. Graham MM, Ghali WA, Faris PD, Galbraith PD, Norris CM, Knudtson ML, et al. Survival after coronary revascularization in the elderly. Circulation 2002;105:2378-84.

17. TIME Investigators. Trial of invasive versus medical therapy in elderly patients with chronic symptomatic coronary-artery disease (TIME): a randomised trial. Lancet 2001;358:951-7.

18. Kaiser C, Kuster GM, Erne P, Amann W, Naegeli B, Osswald S, et al. Risks and benefits of optimised medical and revascularization therapy in elderly patients with angina-on-treatment analysis of the TIME trial. Eur Heart J 2004;25:1036-42.

19. Pfisterer M; Trial of Invasive versus Medical therapy in Elderly patients Investigators. Long-term outcome in elderly patients with chronic angina managed invasively versus by optimized medical therapy: fouryear follow-up of the randomized Trial of Invasive versus Medical therapy in Elderly patients (TIME). Circulation 2004;110:1213-8.

20. Hassani SE, Wolfram RM, Kuchulakanti PK, Xue Z, Gevorkian N, Suddath WO, et al. Percutaneous coronary intervention with drug-eluting stents in very elderly patients: characteristics, clinical presentation, and outcomes. Catheter Cardiovasc Interv 2006;68:36-43.

21. Lopez-Palop R,Carrillo P, Frutos A, Cordero A, Nunez $D$, Toro M, et al. Safety and efficacy of coronary drugeluting stents in very elderly patients. Rev Esp Cardiol 2009;62:1250-9.

22. Chauhan MS, Kuntz RE, Ho KL, Cohen DJ, Popma $\mathrm{JJ}$, Carrozza JP Jr, et al. Coronary artery stenting in the aged. J Am Coll Cardiol 2001;37:856-62. 